\title{
Game Theoretic Analysis of Carbon Emission Reduction and Sales Promotion in Dyadic Supply Chain in Presence of Consumers' Low-Carbon Awareness
}

\author{
Liangjie Xia ${ }^{1}$ and Longfei $\mathrm{He}^{2}$ \\ ${ }^{1}$ School of Business, Tianjin University of Finance and Economics, Tianjin 300222, China \\ ${ }^{2}$ College of Management \& Economics, Tianjin University, Tianjin 300072, China
}

Correspondence should be addressed to Longfei He; helf@tju.edu.cn

Received 4 April 2014; Accepted 3 June 2014; Published 15 July 2014

Academic Editor: Xiaolin Xu

Copyright (C) 2014 L. Xia and L. He. This is an open access article distributed under the Creative Commons Attribution License, which permits unrestricted use, distribution, and reproduction in any medium, provided the original work is properly cited.

\begin{abstract}
The paper studies how the combination of the manufacturer's carbon emission reduction and the retailer's emission reduction relevant promotion impacts the performances of a dyadic supply chain in low-carbon environment. We consider three typical scenarios, that is, centralized and decentralized without or with side-payment. We compare measures of supply chain performances, such as profitabilities, emission reduction efficiencies, and effectiveness, in these scenarios. To improve chain-wide performances, a new side-payment contract is designed to coordinate the supply chain and numerical experiments are also conducted. We find the following. (1) In decentralized setting, the retailer will provide emission cutting allowance to the manufacturer only if their unit product profit margin is higher enough than the manufacturer's, and the emission reduction level of per unit product is a monotonically increasing function with respect to the cost pooling proportion provided by the retailer; (2) the new side-payment contract can coordinate the dyadic supply chain successfully due to its integrating sales promotion effort and emission reduction input, which results in system pareto optimality under decentralized individual rationality but achieves a collective rationality effect in the centralized setting; (3) when without external force's regulation, consumers' low-carbon awareness is to enhance consumers' utility and decrease profits of supply chain firms.
\end{abstract}

\section{Introduction}

Coming with the emerging low-carbon economy and environmental issues over the world, consumers' awareness of low-carbon products gradually arises. Consequently, the product and services having low-carbon features are anticipated to gain more evaluation value by customers. For example, there are some projects that succeed in influencing people's behaviors by using economic instruments, such as incentives, discounts, education, and information sharing; see Geller et al. [1].

To help consumers identify the carbon footprint of products (including carbon emissions of products from manufacturing with raw materials to disposing the finished products) [2], more and more enterprises begin to use carbon labels to track carbon footprint message of products. The adoption of carbon label increases the transparency of the carbon footprint. Therefore, the carbon emission of the product affects the value and utility perceived by consumers directly and thus affects the market demand for the product. Under the influence of awareness of environment, consumers are even willing to pay a higher price for environmentally friendly products than for common products [3]. Affected by this, many large international companies have begun to emphasis their image of emissions reduction. They publish annual environmental and social responsibility reports regularly (such as Toyota Kirloskar Motor and TOTAL) and set their reduction targets. In short, as carbon emission is becoming one of the significant factors affecting product demand increasingly, carbon cutting has become one of the major issues for most firms.

Meanwhile, in many industries, manufacturers are facing growing challenges from retailers; see Inderst and Wey [4]. In more and more industries, it is the retailer, such as 
Wal-Mart, Tesco, and Home Depot, that determines the manufacturing and marketing of products [5]. Retailers in the strong position tend to use their "bargaining power" to take all kinds of unequal trade with suppliers, in order to achieve their aim of delivering the cost and risk, and their actions will cause the whole supply chain to deviate from Pareto optimality [6]. However, enterprises in a supply chain should cooperate while compete. The upstream and the downstream of the supply chain can work together to enhance the product demand, for example, the manufacture focuses on emission reduction while the retailer engages in marketing and promoting related to the products' low-carbon feature. If so, both the manufacturer and the retailer are able to maximize their profits.

Based on the above reasons, we focus on the game between a manufacturer and a retailer in the supply chain considering the impact of carbon cutting and promotion related to the product emission reduction on product demand, under the situation that consumers have the awareness of low carbon. We analyze the decisions of the manufacturer and retailer aiming to maximize their profits. Also, we explore the solution to optimizing the system profit using a new kind of side-payment contract when the manufacturer and the retailer make decisions individually. The new contract can not only increase the profit of the manufacturer and the retailer, but also achieve the rationality and fairness in allocating the incremental profit of the supply chain system.

The studies closely related with our paper focus on supply chain coordination contract designing, corporate decisionmaking, and supply chain operation under low-carbon environment.

There are many previous studies on supply chain coordination contract design. These contracts include buyback contract, revenue sharing contract, quantity discount contract, contract sales rebates, wholesale price contracts, price discounts contracts, and so forth. To find more analytical and detailed commentary on these contracts as well as a detailed review of these studies, readers can refer to Cachon [7] and Leng and Zhu [8]. In addition, Luo and Zhang [9] study a decentralized supply chain with a single supplier and two retailers improving the effectiveness of the supply chain through the side-payment contract. Tang et al. [10] propose a linear side-payment mechanism, so that retailers offer the best promotional level to achieve supply chain coordination.

From early on, people have begun to discuss the impact of carbon emissions on global warming, but companies pay attention to operation under carbon emissions constraints much later [11]. Under carbon emissions constraints, companies tend to adopt more energy-efficient facilities and equipment or transportation facility to reduce emissions. In fact, the same goal could be gained by adjusting the way of operating, transport, and inventory. Even companies can cut more carbon emission with lower cost by this way [12]. But it did not attract enough attention in the academic and private sectors. The studies of business operations under a low-carbon environmental decision-making which are still tiny at this point include the following aspects.

Firstly, some researchers focus on optimizing the transportation mode of supply chain in order to reduce carbon emissions under low-carbon environment. Transportation is a significant source of carbon footprint in supply chain [13]. Hoen et al. made important research on supply chain transportation model selection. Their research showed that in an established network, adjusting transportation model can reduce carbon emissions greatly [14], but the actual decision depends on the carbon related regulations and other practical issues [15].

Secondly, many researchers focus on supply chain network design in low-carbon environment. Companies are different in pressure, marginal cost, and marginal profit of carbon emission reduction because they are in different regions or different in technological and management ability. Those make it possible for companies to optimize the carbon footprint of product by supply chain network design. The optimization of supply chain network is helpful for cutting emission and saving cost at the same time [16]. Considering carbon trading regulation, Ramudhin et al. [17] and Diabat and Simchi-Levi [18] introduced a mixed integer mathematical model for companies to reveal an optimal strategy to meet their carbon cap. Cachon [19] observed that not only the carbon emissions constrain to retailers but also the cost of consumers should be considered in supply chain network design because the network design would affect not only the cost of retailers but also the cost of consumers.

Thirdly, supply chain coordination considering lowcarbon regulations is an important topic. Product carbon footprint is the total emission across its life cycle; it is difficult for enterprises to optimize carbon footprint in supply chain on their own, so cooperation between the upstream and the downstream is essential for carbon emission reduction [20].

In order to minimize the product carbon footprint, it must be decomposed into processes of the supply chain firstly. Caro et al. [21] introduced an effective model to solve this problem.

In the field of supply chain coordination, $\mathrm{Du}$ et al. [22] investigated the behavior and decision-making of each member in the emission dependent supply chain with an emission permit supplier and an emission dependent firm considering the "cap-and-trade" regulation. Xia et al. [23] analyzed the joint carbon emission reduction between the manufacturer and the supplier in considering "cap-andtrade" system and introduced transfer payment contract to optimize carbon cutting and the supply chain profit. Yang et al. [24] compared the impact of two carbon regulations, mandatory emission reduction, and carbon tax on carbon emission and the cost of supplier, retailer, and supply chain system by means of system dynamics.

In this study, being different from existing research, we take consumers' low-carbon awareness into consideration and consider emissions reduction and promotion about lowcarbon product as the factors affecting the demand function to study promotion decisions of retailers and the carbon emission reduction decisions of manufacturers. Besides, we established a new side-payment contract, with that both sides in the game can achieve the collective optimality when making individual's decisions. The contract design can not only meet demand for increasing revenue but also solve rationality 
and fairness issues of allocating incremental revenue in the system and then achieve the supply chain coordination.

The rest of the paper is organized as follows. In Section 2, we describe the problem and give out the general model on this problem. In Section 3, centralized decision model is constructed to be benchmarked for afterwards settings. In Sections 4 and 5, we develop the decentralized model via Stackelberg game without or with side-payment. In Section 6, the side-payment contract is used to coordinate the supply chain compared to the centralization scenario. In Section 7, we conduct numerical study to examine models in afore sections. In Section 8, this study comes to the end by summarizing main insights and future extensions.

\section{Problem Formulation and General Model}

This paper focuses on a dyadic supply chain composed of a manufacturer as follower and a retailer as leader in Stackelberg games. Considering consumer's low-carbon awareness, the manufacturer engaged in carbon emissions reduction (deciding the volume of reduction of per unit product), and the retailer focuses on product promoting related to its low-carbon feature (deciding the promotion level). Also, the retailer decides the distribution of emission reduction cost between manufacturer and retailer (showed as Figure 1).

To simplify the study and without loss of generality, this paper is based on the following assumptions: (1) only one product is involved in the supply chain; (2) stock and inventory backlog is not considered; (3) the retailers and manufacturers earn a fixed profit per unit product (before deducting the investment of promotion and emission reduction); (4) initial emission of per unit of product is 1 , so the emission reduction of per unit product is less than 1 ; the promotion level is also less than 1.

Some parameters involved are given as follows: $D S, D C$, $C, D$, and $D T$ denote Stackelberg game model with sidepayment, Stackelberg game model without side-payments, centralized decision-making model, the initial dynamic game model, and side-payment self-executing contract model, respectively.

\section{Decision Variables}

$q$ : Retailer's promotion level, $0 \leq q<1$

$\theta$ : The proportion of emission reduction cost the retailer takes, $0 \leq \theta<1$

$e$ : The emission reduction of per unit product, $0 \leq e<1$.

\section{Parameters}

$a$ : Market size without considering carbon emission reduction and promotion, $a>0$

$D$ : Product demand

$b$ : Constant coefficient, $b>0$

$\rho_{m}$ : Manufacturer's profit of per unit product without considering carbon cutting cost, $\rho_{m}>0$ $\rho_{r}$ : Retailer's profit of per unit product without considering promotion cost, $\rho_{r}>0$

$\gamma$ : The coefficient of carbon emission's effect on demand, $\gamma>0$

$\delta$ : The coefficient of promotion's effect on demand, $\delta>0$

$\Pi_{m}$ : The profit of manufacturer

$\Pi_{r}$ : The profit of retailer

$\Pi$ : The profit of the supply chain system.

In the case of the current growing concern about carbon emissions, it has grown up to be an effective mean for enterprises to improve product demand by reducing carbon emissions and promoting products according to its carbon trait.

Since carbon emission of product affects consumer's utility directly, companies can enhance the market demand of product by cutting carbon emission. Laroche et al. [25] figured out that the more consumers cared about environment, the higher price consumers would be willing to pay for green products. Plambeck [26] also indicated that companies could increase product market share and consumer confidence by disclosing the information about carbon emission. Therefore, in a low-carbon environment, in addition to providing quality products and competitive price, reducing carbon emissions and disclosing information related to carbon are also new strategies for companies to increase market demand.

Retailer's sale promotion related to low-carbon trait of product can improve product marketing demands too. Liu et al. [3] pointed out that the main benefit increment of company selling environmentally friendly production resulted from the product demand increment caused by consumer's environmental awareness, and eco-friendly companies should adopt some measures in marketing process to improve consumer's environmental awareness and turn nongreen consumers to green consumers. In practice, large retail stores often adopt advertising and promotion related to the product's low-carbon feature to shape consumer's value and influence the consumption action [27]. Taylor [28] demonstrates that the retailer's promotional effort is one of the crucial factors affecting market demand.

Product demand increases with carbon emission reduction, but the demand increment decreases with emission reduction. It is same as the retailer's promotional effort. Learning from the research of Geylani et al. [5], Yue et al. [29], and Szmerekovsky and Zhang [30], this paper expresses the demand function as $D=a^{\prime}-b^{\prime} p-b e^{-\gamma} q^{-\delta} ; p$ represents the sales price. The improvement of consumer's low-carbon awareness is a gradual process since it is affected by consumer cognition. Currently, consumer's low-carbon awareness is not very high. So it is reasonable to assume that the companies' aim of emission reduction and related promotion is not to enhance the sale price and gain higher average profit but to increase market demand. In other words, the sale price and average profit of the low-carbon product are exogenous. Therefore, $p=c_{m}+c_{r}+\rho_{m}+\rho_{r}, c_{m}$ and $c_{r}$ denote the cost of per unit product for manufacturer and retailer, respectively. 


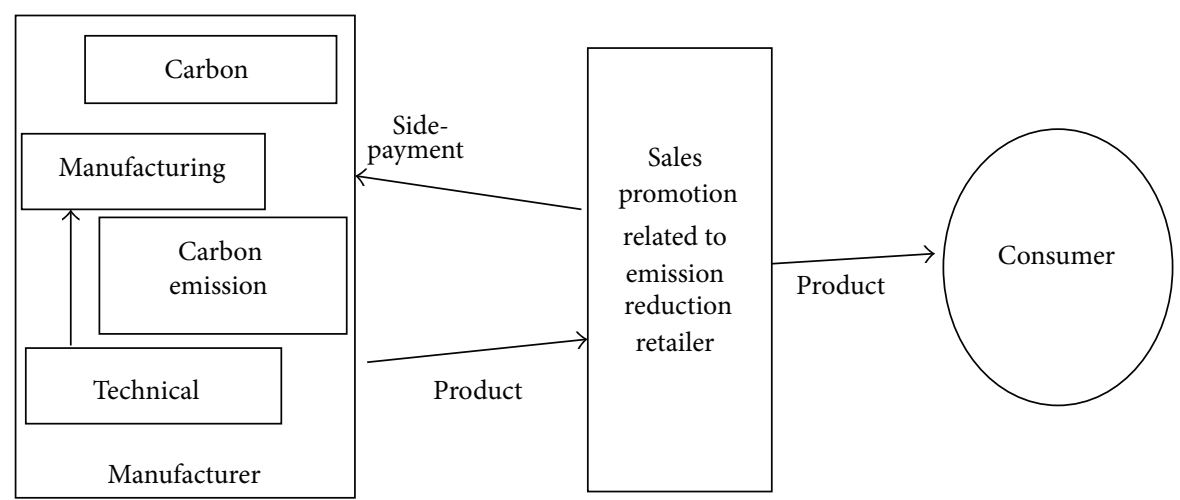

FIGURE 1: Manufacturer's emission reduction, retailer- promoting cooperation, and competition.

Let $a=a^{\prime}-b^{\prime}\left(c_{m}+c_{r}+\rho_{m}+\rho_{r}\right)$; the demand function of product could be expressed as

$$
D=a-b e^{-\gamma} q^{-\delta} .
$$

The costs of carbon emissions reduction and promotion are convex in the emissions reduction of per unit product and promotion level, respectively [31]. So the cost of carbon emissions reduction $(C(e))$ and the cost of promotion $(C(q))$ can be expressed as $(1 / 2) u_{m} e^{2}$ and $(1 / 2) u_{r} q^{2}$, respectively.

\section{Centralized Decision-Making Model $(C)$}

The double marginal effect resulted from decentralized decision-making in supply chain usually results in a suboptimal profit of the system. If there is a stimulus conditions or a binding agreement which could make the participators make decision centrally and get more profits, centralized decision-making is possible. Under the situation of centralized decision-making, a system integrator replaces two game participants to make decisions to optimize the total profit of the system. The objective function could be expressed as

$$
\max _{0 \leq e<1,0 \leq q<1} \Pi^{C}=\left(\rho_{m}+\rho_{r}\right)\left(a-b e^{-\gamma} q^{-\delta}\right)-\frac{1}{2} u_{m} e^{2}-\frac{1}{2} u_{r} q^{2} .
$$

Since the Hessian matrix is negative definite, the optimal promotion levels and reductions are as follows:

$$
\begin{aligned}
q^{C}= & {\left[\frac{\delta b\left(\rho_{m}+\rho_{r}\right)}{u_{r}}\right]^{(\gamma+2) /(2 \delta+2 \gamma+4)} } \\
& \times\left[\frac{\gamma b\left(\rho_{m}+\rho_{r}\right)}{u_{m}}\right]^{-\gamma /(2 \delta+2 \gamma+4)}, \\
e^{C}= & {\left[\frac{\delta b\left(\rho_{m}+\rho_{r}\right)}{u_{r}}\right]^{-\delta /(2 \delta+2 \gamma+4)} } \\
& \times\left[\frac{\gamma b\left(\rho_{m}+\rho_{r}\right)}{u_{m}}\right]^{(\delta+2) /(2 \delta+2 \gamma+4)} .
\end{aligned}
$$

\section{Stackelberg Game without Side-Payments $(D C)$}

In the Stackelberg game between a manufacturer and a leading retailer, the retailer decides the level of sale promotion firstly and the manufacturer determines the emission reduction of per unit product secondly. Objective functions of manufacturer and retailer are shown as follows:

$$
\begin{aligned}
& \max _{0 \leq e<1} \Pi_{m}^{D C}=\rho_{m}\left(a-b e^{-\gamma} q^{-\delta}\right)-\frac{1}{2} u_{m} e^{2}, \\
& \max _{0 \leq q<1} \Pi_{r}^{D C}=\rho_{r}\left(a-b e^{-\gamma} q^{-\delta}\right)-\frac{1}{2} u_{r} q^{2} .
\end{aligned}
$$

Since $\partial^{2} \Pi_{m}^{D C} / \partial e^{2}=-\gamma(\gamma+1) \rho_{m} b e^{-\gamma-2} q^{-\delta}-u_{m}<0, \Pi_{m}^{D C}$ is the concave function of $e$. Let $\partial \Pi_{m}^{D C} / \partial e=\gamma \rho_{m} b e^{-\gamma-1} q^{-\delta}-$ $u_{m} e=0 ; e$ could be obtained as follows:

$$
e=\left(\frac{\gamma \rho_{m} b}{u_{m}}\right)^{1 /(\gamma+2)} q^{-\delta /(\gamma+2)}
$$

Substitute (6) into (5) and take the derivative of q; thus we obtain

$$
\begin{aligned}
\frac{\partial^{2} \Pi_{r}^{D C}}{\partial q^{2}}= & -\frac{2 \delta(2 \delta+\gamma+2)}{(\gamma+2)^{2}} b \rho_{r}\left(\frac{\gamma \rho_{m} b}{u_{m}}\right)^{-\gamma /(\gamma+2)} \\
& \times q^{(-2 \gamma-2 \delta-4) /(\gamma+2)}-u_{r}<0,
\end{aligned}
$$

so $\Pi_{r}^{D C}$ is concave in $q$.

$$
\text { Let } \partial \Pi_{r}^{D C} / \partial q=(2 \delta /(\gamma+2)) b \rho_{r}\left(\gamma \rho_{m} b / u_{m}\right)^{-\gamma /(\gamma+2)}
$$
$q^{(-2 \delta-\gamma-2) /(\gamma+2)}-u_{r} q=0$; the optimal promotion level is obtained as

$$
q^{D C}=\left[\frac{2 \delta b \rho_{r}}{u_{r}(\gamma+2)}\right]^{(\gamma+2) /(2 \delta+2 \gamma+4)}\left(\frac{\gamma \rho_{m} b}{u_{m}}\right)^{-\gamma /(2 \delta+2 \gamma+4)} .
$$

Substitute $q^{D C}$ into (6); the optimal emission reduction could be expressed as

$$
e^{D C}=\left[\frac{2 \delta b \rho_{r}}{u_{r}(\gamma+2)}\right]^{-\delta /(2 \delta+2 \gamma+4)}\left(\frac{\gamma \rho_{m} b}{u_{m}}\right)^{(\delta+2) /(2 \delta+2 \gamma+4)} .
$$




\section{Stackelberg Game with Side-Payments (DS)}

Product demand increases with carbon emission reduction. It provides opportunity for both the manufacturer and the retailer to enhance their profit while only the cost of manufacturer increases. In the supply chain dominating by retailer, a side-payment contract requiring the retailer sharing part of manufacturer's cost of emission reduction will encourage the manufacturer to improve its emission reduction. For the retailers, as long as cost increment is lower than profits increment caused by emission reduction, they are willing to share the carbon cutting cost. Assume that the proportion of emission reduction cost taken by the retailer is $\theta$; both players still perform Stackelberg game. The retailer determines the promotion level $(q)$ and the proportion of cost allocation $(\theta)$; then manufacturer determines the emission reduction of per unit products $(e)$. The objective functions of both players could be expressed as follow:

$$
\begin{aligned}
& \max _{0 \leq e<1} \Pi_{m}^{D S}=\rho_{m}\left(a-b e^{-\gamma} q^{-\delta}\right)-\frac{1}{2}(1-\theta) u_{m} e^{2}, \\
& \max _{\substack{0 \leq q<1, 0 \leq \theta<1}} \Pi_{r}^{D S}=\rho_{r}\left(a-b e^{-\gamma} q^{-\delta}\right)-\frac{1}{2} \theta u_{m} e^{2}-\frac{1}{2} u_{r} q^{2} .
\end{aligned}
$$

With backward induction method, the optimal emission reduction level can be obtained as

$$
e=\left(\frac{\gamma b \rho_{m}}{u_{m}-\theta u_{m}}\right)^{1 /(\gamma+2)} q^{-\delta /(\gamma+2)}
$$

Obviously, $e=\left(\gamma b \rho_{m} / u_{m}\right)^{1 /(\gamma+2)} q^{-\delta /(\gamma+2)}$ is the particular case of $e=\left(\gamma b \rho_{m} /\left(u_{m}-\theta u_{m}\right)\right)^{1 /(\gamma+2)} q^{-\delta /(\gamma+2)}$ when $\theta=0$. We obtain $\partial e / \partial \theta>0, \partial e / \partial \rho_{m}>0$, and $\partial e / \partial q<0, \partial e / \partial u_{m}<0$ from (6) and (12). So we draw conclusions as follows.

Conclusion 1. In the Stackelberg game, (1) the emission reduction level $(e)$ decreases with the promotional level $(q)$ whether a side-payment exits or not; (2) with a side-payment, the emission reduction level $e$ increases with the cost sharing proportion $(\theta)$.

In (6) and (12), $e$ is not the optimal emission reduction level but the emission reduction reaction function about promotion level $(q)$. It is the decision basis of the manufacturer. From (6) and (12), we know that $e$ increases with $\theta$. It means that it is effective for the retailer to encourage the manufacturer to enhance the emission reduction level by sharing its carbon cutting cost. So it is possible for the two players to cooperate in emission reduction. At the same time, the manufacturer's emission reduction level decreases with the promotion level. It means that "free riding" is possible in cooperation. In other words, the manufacturer might cut down its carbon cutting level while the retailer enhances the promotion level. So the retailer should take measures to prevent or alleviate "free riding." Providing side-payment for emission reduction is one of the effective measures.
Substituting (12) into (11), then the optimal cost-sharing proportion $\theta$, promotion level $q$, and emission reduction level could be obtained as

$$
\begin{aligned}
\theta^{D S}= & \begin{cases}\frac{2 \rho_{r}-\gamma \rho_{m}-2 \rho_{m}}{2 \rho_{r}-\gamma \rho_{m}}, & \text { if } \rho_{r}>\frac{1}{2}(\gamma+2) \rho_{m}, \\
0, & \text { if } \rho_{r} \leq \frac{1}{2}(\gamma+2) \rho_{m},\end{cases} \\
q^{D S}= & {\left[\frac{\gamma b\left(2 \rho_{r}-\gamma \rho_{m}\right)}{2 u_{m}}\right]^{-\gamma /(2 \gamma+2 \delta+4)} } \\
& \times\left[\frac{\delta b\left(2 \rho_{r}-\gamma \rho_{m}\right)}{2 u_{r}}\right]^{(\gamma+2) /(2 \gamma+2 \delta+4)}, \\
e^{D S}= & {\left[\frac{\gamma b\left(2 \rho_{r}-\gamma \rho_{m}\right)}{2 u_{m}}\right]^{(\delta+2) /(2 \gamma+2 \delta+4)} } \\
& \times\left[\frac{\delta b\left(2 \rho_{r}-\gamma \rho_{m}\right)}{2 u_{r}}\right]^{-\delta /(2 \gamma+2 \delta+4)}
\end{aligned}
$$

Based on the above analysis, we can get Conclusions 2, 3, and 4 shown as follows.

Conclusion 2. In Stackelberg game, the retailer will share the manufacturer's carbon cutting cost only if $\rho_{r}>(1 / 2)(\gamma+2) \rho_{m}$, and the cost allocation increases with $\rho_{r}$ but decreases with $\rho_{m}$.

Conclusion 2 shows that the retailer will share the emission reduction cost only when its profit of per unit product is higher enough than that of the manufacturer. Since $\partial \theta^{D S} / \partial \rho_{r}>0$ and $\partial \theta^{D S} / \partial \rho_{m}<0$, the higher $\rho_{r}$ or lower $\rho_{m}$ is, the more emission reduction cost the retailer will bear. Cost sharing will encourage the manufacture to enhance carbon cutting level and then improve the product demand. So the retailer will share the manufacturer's cost as long as the cost increment resulted from cost sharing is lower than the profit increment resulted from demand improvement. On the other hand, the higher the $\rho_{r}$ is the more the retailer benefits from product demand increment and the more he is capable of sharing the manufacturer's cost. So the higher $\rho_{r}$ is, the higher $\theta$ is. On the contrary, the higher $\rho_{m}$ is, the more profit the manufacturer benefits from product demand improvement, so the lower cost-sharing level the retailer takes.

Since $\partial e^{D S} / \partial \rho_{m}<0$ and $\partial e^{D S} / \partial \rho_{r}>0$, the optimal emission reduction level $e^{D S}$ decreases with the manufacturer's profit of per unit product $\rho_{m}$ and increases with the retailer's profit of per unit product $\rho_{r}$. In order to balance the players' profit and encourage the manufacturer to improve carbon cutting, the retailer needs to share the manufacturer's emission reduction cost; that is, $\theta^{D S}>0$.

Actually, the retailer will not share the manufacturer's cost if $\rho_{r} \leq(1 / 2)(\gamma+2) \rho_{m}$, and the players will perform the Stackelberg game without side-payments, so the optimal emission level and promotion level will be equal as $e^{D C}$ and $q^{D C}$, respectively. 
Conclusion 3. (1) The optimal promotion level increases with $\rho_{r}$ and $u_{m}$ but decreases with $\rho_{m}$ and $u_{r}$ whether or not side-payments exist. (2) The optimal emission reduction level increases with $u_{r}$ but decreases with $u_{m}$ whether or not a side-payments exist. (3) The optimal emission reduction level increases with $\rho_{m}$ but decreases with $\rho_{r}$ without sidepayments existing, and it is contrary to the case of sidepayments existing.

No matter what kind of game is performed, the emission reduction level reaches the optimal value when the manufacturer's marginal cost of carbon emission is equal to its marginal income. In fact, the manufacturer's profit of per unit of product disregarding emission reduction, $\rho_{m}$, is the marginal income. Since $\rho_{m}$ is fixed, the higher $u_{m}$ is the lower emission reduction level $e$ is. Similarly, the higher the retailer's promotion cost is, the lower promotion level is, and the more important enhancing emission reduction level is for improving product demand. So the optimal promotion level increases with $u_{m}$ and decreases with $u_{r}$.

The higher retailer's profit of per unit product $\left(\rho_{r}\right)$ is, the more profit retailer gains from market demand improvement, and the greater incentive the retailer has to enhance promotion level. The higher the manufacturer's profit of per unit product $\left(\rho_{m}\right)$ is, the greater the retailer relies on the manufacturer to improve market demand. It is same for the manufacturer's optimal emission reduction level in case of Stackelberg game without side-payment. But the higher $\rho_{r}$ is, the higher $\theta^{D S}$ is. It means that the more carbon cutting cost the retailer will take, the less cost the manufacturer will take by itself. In fact, the manufacturer's actual marginal cost of emission reduction decreases. So the optimal emission reduction level will increase. In contrary, the higher $\rho_{m}$ is, the lower $\theta^{D S}$ is, and the lower optimal emission reduction level is.

Conclusion 4. (1) In Stackelberg game, the optimal level of emission reduction with side-payment is higher than that without side-payment; that is, $e^{D S}>e^{D C}$. (2) In the Stackelberg game, the optimal promotion level with sidepayment is higher than that without side-payment if $\left(\left(2 \rho_{r}-\right.\right.$ $\left.\left.\gamma \rho_{m}\right) / 2\right)^{2 /(2 \gamma+2 \delta+4)}>\left(2 \rho_{r} /(\gamma+2)\right)^{(\gamma+2) /(2 \delta+2 \gamma+4)} \rho_{m}{ }^{-\gamma /(2 \delta+2 \gamma+4)}$; that is, $q^{D S}>q^{D C}$; otherwise, $q^{D S} \leq q^{D C}$. (3) Cost allocation related to emission reduction between the retailer and the manufacturer results in a Pareto improvement of the supply chain profit; that is, $\Pi^{D S}>\Pi^{D C}, \Pi_{m}^{D S}>\Pi_{m}^{D C}$, and $\Pi_{r}^{D S}>$ $\Pi_{r}^{D C}$.

Conclusion 4 is proved in the appendix.

Conclusion 4 shows that the retailer realizes encouraging the manufacturer to improve emission reduction by sharing its cost, but it is determined by the value of parameters whether the promotion level is improved or not. Since $\Pi^{D S}>$ $\Pi^{D C}, \Pi_{m}^{D S}>\Pi_{m}^{D C}$, and $\Pi_{r}^{D S}>\Pi_{r}^{D C}$, the profits of the supply chain system and those of both players are improved by cost allocation between the players. In other words, the retailer would be stimulated to share the manufacturer's cost as long as $\rho_{r}>(1 / 2)(\gamma+2) \rho_{m}$. So great possibility for cooperation related to carbon cutting between the players exists.

\section{Supply Chain Coordination Based on Side-Payment Contract Design}

The optimal decisions of the players in case of centralized decision-making and Stackelberg equilibrium with a sidepayment or not have been analyzed, respectively. The Pareto equilibrium point of the supply chain is achieved as $\left(q^{c}, e^{c}\right)$ without considering the cost of resource allocation between the manufacturer and the retailer. The corresponding system profit is the benchmark of the supply chain profit. Obviously, this optimal system profit could not be obtained because of double marginalization between the players in case of decentralized decision-making. But centralized decision-making is possible as long as both players could gain more profit than that in case of noncooperation. Of course, two important conditions, participation constraint and incentive compatibility constraint, are necessary for centralized decision-making. Also, reasonable distribution of the profit increment resulting from centralized decision-making is essential.

In the following section, a new side-payment selfexecuting contract (SSEC) is designed to equalize the game equilibrium between the players in case of decentralized decision-making and that in case of centralized decisionmaking. Actually, SSEC is firstly proposed by $\mathrm{He}$ and Zhao [32], to which one can refer for learning more details in inducing and designing processes of SSEC this theory and mechanism method. Then the Pareto optimality of the system is realized and both the participation constraint and the incentive compatibility constraint are met. Assume the profits of manufacturers and retailers without side-payment selfexecuting contracts are $\Pi_{m}^{D}(q, e)$ and $\Pi_{r}^{D}(q, e)$, and those with side-payment self-executing contracts are $\Pi_{m}^{D T}(q, e)$ and $\Pi_{r}^{D T}(q, e)$, respectively.

For convenience, a nonlinear function of $q$ and $e$ is assumed as $T(q, e)=x q^{2}+y e^{2}$ and the side-payment function is $\widetilde{T}(q, e)=x q^{2}+y e^{2}+g$. In which, $x$ and $y$ are given as nonnegative constants, and $g$ is a constant. Then the objective functions of manufacturer and retailer could be defined as follows, respectively (the real shift direction of side-payment is decided by sigh of $\widetilde{T}(q, e))$ :

$$
\begin{aligned}
& \max _{0 \leq e<1} \Pi_{m}^{D T}(q, e)=\rho_{m}\left(a-b e^{-\gamma} q^{-\delta}\right)-\frac{1}{2} u_{m} e^{2}+T(q, e)+g, \\
& \max _{0 \leq q<1} \Pi_{r}^{D T}(q, e)=\rho_{r}\left(a-b e^{-\gamma} q^{-\delta}\right)-\frac{1}{2} u_{r} q^{2}-T(q, e)-g .
\end{aligned}
$$

Both $\Pi_{m}^{D T}(q, e)$ and $\Pi_{r}^{D T}(q, e)$ could be proved as the concave functions of $e$ and $q$. A Stackelberg game is played between the retailer and the manufacturer. The retailer as the leader makes decision firstly; then the manufacturer decides the emission reduction level. In this case, the optimal decisions of the players could be obtained as follows:

$$
\begin{aligned}
q^{D T}= & \left(\frac{\gamma b \rho_{m}}{u_{m}-2 y}\right)^{-\gamma /(2 \gamma+2 \delta+4)} \\
& \times\left[\frac{2 \delta b\left(\gamma y \rho_{m}+u_{m} \rho_{r}-2 y \rho_{r}\right)}{(\gamma+2)\left(u_{m}-2 y\right)\left(u_{r}-2 x\right)}\right]^{(\gamma+2) /(2 \gamma+2 \delta+4)},
\end{aligned}
$$




$$
\begin{aligned}
e^{D T}= & \left(\frac{\gamma b \rho_{m}}{u_{m}-2 y}\right)^{(\delta+2) /(2 \gamma+2 \delta+4)} \\
& \times\left[\frac{2 \delta b\left(\gamma y \rho_{m}+u_{m} \rho_{r}-2 y \rho_{r}\right)}{(\gamma+2)\left(u_{m}-2 y\right)\left(u_{r}-2 x\right)}\right]^{-\delta /(2 \gamma+2 \delta+4)}
\end{aligned}
$$

If the participation constraint and the incentive compatibility constraint are satisfied, the decision-making in Stackelberg game with the new side-payment self-executing contract will be the same as that in centralized decisionmaking. The participation constraint ensures that both of the players are willing to participate in the cooperation. Incentive compatibility constraint makes sure that the decision-making according to individual rationality equals to the optimal Pareto equilibrium.

Participation Constraint. $\Pi_{m}^{D T}(q, e) \geq \Pi_{m}^{D}(q, e) ; \Pi_{r}^{D T}(q, e) \geq$ $\Pi_{r}^{D}(q, e)$. Both the manufacturer and the retailer are able to gain more profit in the case of side-payment self-executing contract than that before this contract is adopt.

Incentive Compatibility Constraint. $\left(q^{D T}, e^{D T}\right)=\left(q^{C}, e^{C}\right)$. The game equilibrium in case of side-payment self-executing contracts is the same as that in case of centralized decisionmaking.

To demonstrate the side-payment function, the value of $x, y$, and $g$ is required. According to incentive compatibility constraint, and setting $q^{D T}=q^{C}, e^{D T}=e^{C}$, we can obtain

$$
\begin{gathered}
x=\frac{1}{2} u_{r}-\frac{u_{r} \rho_{r}\left(\gamma \rho_{m}+\rho_{m}-\rho_{r}\right)}{(\gamma+2)\left(\rho_{m}^{2}-\rho_{r}^{2}\right)}, \\
y=\frac{u_{m} \rho_{r}}{\rho_{m}+\rho_{r}} .
\end{gathered}
$$

Thus $\widetilde{T}(q, e)=\left[(1 / 2) u_{r}-u_{r} \rho_{r}\left(\gamma \rho_{m}+\rho_{m}-\rho_{r}\right) /(\gamma+\right.$ 2) $\left.\left(\rho_{m}{ }^{2}-\rho_{r}{ }^{2}\right)\right] q^{2}+\left(u_{m} \rho_{r} /\left(\rho_{m}+\rho_{r}\right)\right) e^{2}+g$. Then, $\widetilde{T}(q, e)$ could be determined as long as the value of $g$ is determined.

Much of the existing literature adopts Nash bargaining theory to distribute the incremental profit of the system between the players in perfect information static game. Nash bargaining theory fits for distributing profit in cooperative game. And a binding agreement is necessary for cooperative game. In fact, since the power structure of the supply chain is unbalanced, the dominant player would not be willing to participate in cooperative game. So the Nash bargaining solution is not always realistic. On the other hand, frequently trades between the upstream and the downstream of the supply chain are similar to the multiperiod bargaining game model. So it is reasonable to adopt Rubinstein bargaining game to simulate the process of profit allocation.

Let $\theta_{r}$ and $\theta_{m}$ denote the discount factors of retailer and manufacturer, respectively. And let $\delta_{r}$ and $\delta_{m}$ denote the share of profit increment resulting from cooperation of the retailer and the manufacturer, respectively $\left(\delta_{r}+\right.$ $\left.\delta_{m}=1\right)$. Rubinstein [33] has proved that there is a unique subgame refining Nash equilibrium in an indefinite duration alternating offers game which can be expressed as $\left(\delta_{r}^{*}, \delta_{m}^{*}\right)=$ $\left(\left(1-\theta_{r}\right) /\left(1-\theta_{r} \theta_{m}\right),\left(\theta_{r}-\theta_{r} \theta_{m}\right) /\left(1-\theta_{r} \theta_{m}\right)\right)$. The discount factor usually can be regarded as the game players' patience degree. The larger the discount factor is, the more patient the game participant is and will have greater influence on the game. And the more patient participant will suffer less lost or opportunity cost resulted from time delay than the less patient participant. [i] In this paper,

$$
\begin{aligned}
\Delta \Pi_{m} & =\Pi_{m}^{C}\left(q^{C}, e^{C}\right)+T\left(q^{C}, e^{C}\right)+g-\Pi_{m}^{D}\left(q^{D}, e^{D}\right) \\
& =\delta_{m} \Delta \Pi, \\
\Delta \Pi_{r} & =\Pi_{r}^{C}\left(q^{C}, e^{C}\right)-T\left(q^{C}, e^{C}\right)-g-\Pi_{r}^{D}\left(q^{D}, e^{D}\right) \\
& =\delta_{r} \Delta \Pi,
\end{aligned}
$$

$$
\Delta \Pi_{C}=\Delta \Pi_{m}+\Delta \Pi_{r} .
$$

Based on (17), $g$ could be obtained as follows:

$$
\begin{aligned}
g= & \delta_{r}\left[\Pi_{m}^{C}\left(q^{C}, e^{C}\right)+T\left(q^{C}, e^{C}\right)-\Pi_{m}^{D S}\left(q^{D S}, e^{D S}\right)\right] \\
& -\delta_{m}\left[\Pi_{r}^{C}\left(q^{C}, e^{C}\right)+T\left(q^{C}, e^{C}\right)-\Pi_{r}^{D S}\left(q^{D S}, e^{D S}\right)\right] .
\end{aligned}
$$

According to the result of game equilibrium above and (18), the value of $g$ can be determined. Thus, the new sidepayment self-executing contract can be identified. In decentralized decision-making situation, the players will make their own optimal decisions based on individual rationality. In order to achieve the centralized decision-making system performance in decentralized decision-making set, anyone of the payers could provide the side-payment to the other player to influence their payoff functions.

\section{Numerical Analysis}

In the following section, numerical analysis is adopted to explore the impact of $\gamma$ and $\delta$ on the decision-making and profit of the retailer and manufacturer. The related parameters are set as follows.

In order to analyze the impact of $\gamma$, let $a=800, b=40$, $\rho_{m}=10, \rho_{r}=25, \delta_{r}=0.6, \delta_{m}=0.4, u_{m}=10000, u_{r}=12000$, $\delta=4$, and $1 \leq \gamma \leq 3$.

In order to analyze the impact of $\delta$, let $a=800, b=40$, $\rho_{m}=10, \rho_{r}=30, \delta_{r}=0.6, \delta_{m}=0.4, u_{m}=10000, u_{r}=14000$, $\gamma=2.2$, and $1 \leq \delta \leq 5$.

The result of numerical analysis is shown from Figure 3 to Figure 11. Shown as from Figure 3 to Figure 11, conclusion 1 to conclusion 4 are proved and some important findings are discovered.

(1) In case of decentralized decision the profits of both players increase because of the new side-payment selfexecuting contract, and the optimal system profit is equal to that in centralized decision set. It is proved that the requirements of participation constraint, incentive compatibility, and justice of profit allocation are met.

(2) As shown in Figure 2, no matter in decentralized decision or in centralized decision, the optimal emission reduction level of the manufacturer increases with $\gamma$. The 


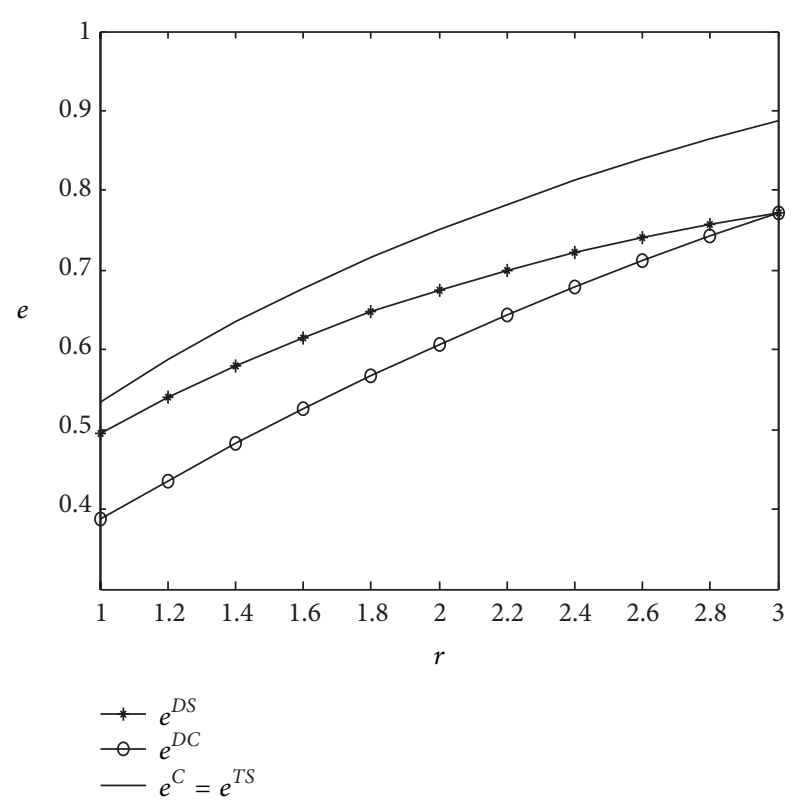

FIGURE 2: Impact of $\gamma$ on optimal emission reduction.

optimal emission reduction levels in both of the centralized decision and the Stackelberg game with side-payment are higher than those in Stackelberg game without side-payment. From the case without side-payment to which a side-payment contract is executed, the increment of optimal emission reduction level decreases with $\gamma$.

The bigger $\gamma$ is, the greater emission reduction affects product demand and the more effective it is to improve product demand by means of enhancing carbon cutting level. For a rational decision maker, efficiency of profit improving is the only criterion for adopting emission reduction or sale promotion to enhance product demand. So the optimal emission reduction level increases with $\gamma$ whether in centralized decision or not.

It has been proved that the optimal emission reduction with side-payment is more than that without side-payment in Stackelberg game.

When $\rho_{r}>(1 / 2)(\gamma+2) \rho_{m}, \theta^{D S}=\left(2 \rho_{r}-\gamma \rho_{m}-2 \rho_{m}\right) /\left(2 \rho_{r}-\right.$ $\left.\gamma \rho_{m}\right)$ and $\partial \theta^{D S} / \partial \gamma<0$. It means that $\theta^{D S}$ decreases with $\gamma$. In other words, the higher $\gamma$ is, the lower the proportion of emission reduction cost the retailer will take, and the less effective to encourage the manufacturer to improve emission reduction. Therefore, from the game without a side-payment contract to that with a side-payment contract, the increment of emission reduction decreases with $\gamma$ until $\rho_{r} \leq(1 / 2)(\gamma+$ 2) $\rho_{m}\left(\theta^{D S}=0\right)$.

(3) As shown in Figure 3, the optimal promotion level decreases with $\gamma$ no matter in case of decentralized decision or in centralized decision.

The bigger $\gamma$ is, the lower relative importance of promotion is for product demand improvement. So the optimal promotion level decreases with $\gamma$.

As shown in Figure 3 and proved previously, the optimal emission reduction level with side-payment is higher than

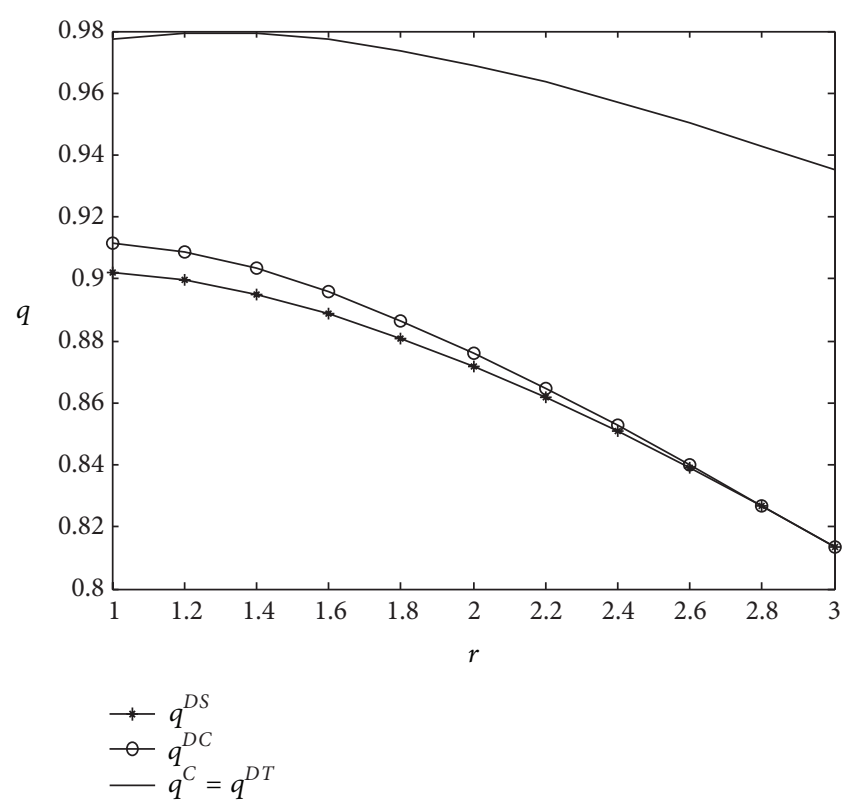

FIGURE 3: Impact of $\gamma$ on optimal promotion level.

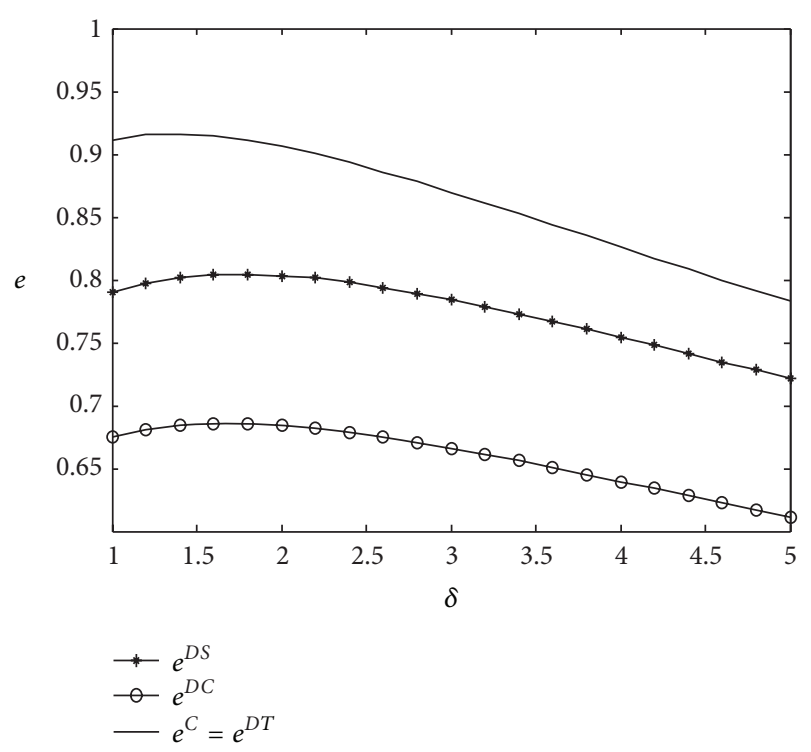

FIGURE 4: Impact of $\delta$ on optimal emission reduction.

that without side-payment if $\left(\left(2 \rho_{r}-\gamma \rho_{m}\right) / 2\right)^{2 /(2 \gamma+2 \delta+4)} \leq$ $\left(2 \rho_{r} /(\gamma+2)\right)^{(\gamma+2) /(2 \delta+2 \gamma+4)} \rho_{m}{ }^{-\gamma /(2 \delta+2 \gamma+4)}$. Also, an opposite conclusion could be obtained if $\left(\left(2 \rho_{r}-\gamma \rho_{m}\right) / 2\right)^{2 /(2 \gamma+2 \delta+4)}>$ $\left(2 \rho_{r} /(\gamma+2)\right)^{(\gamma+2) /(2 \delta+2 \gamma+4)} \rho_{m}{ }^{-\gamma /(2 \delta+2 \gamma+4)}$.

At the same time, Figure 3 proves again that the retailer does not share the manufacturer's emission reduction cost if $\rho_{r} \leq(1 / 2)(\gamma+2) \rho_{m}$, and it means that the side-payment is zero.

(4) As shown in Figures 4 and 5, the optimal promotion level of the retailer increases with $\delta$, and the optimal emission reduction level increases first and then decreases with $\delta$ 


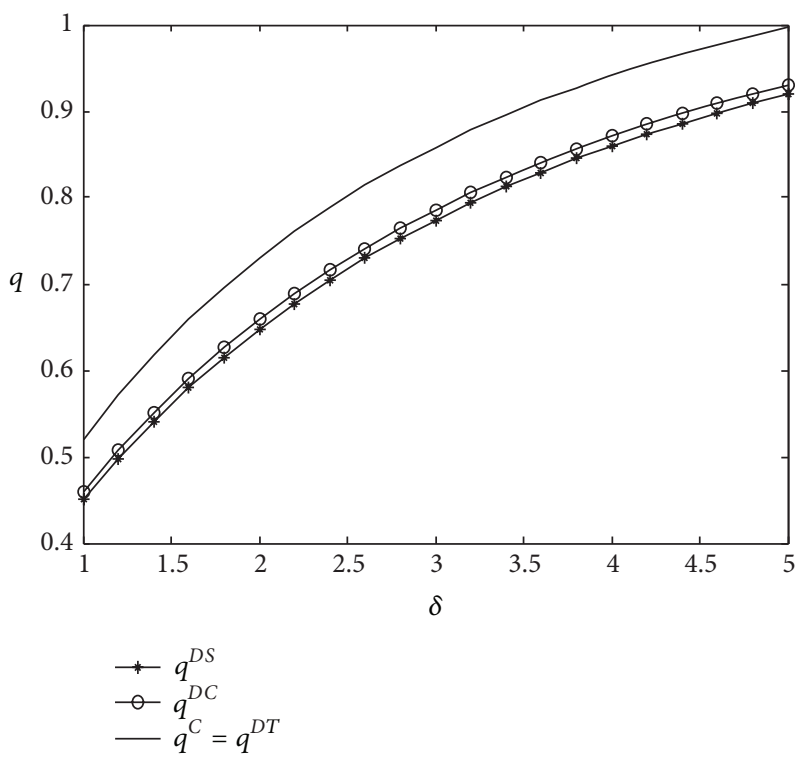

Figure 5: Impact of $\delta$ on optimal promotion level.

whether in case of decentralized decision or centralized decision. The increment of optimal emission reduction decreases with $\delta$ but that of the optimal promotion level increases with $\delta$ between different decision-making modes.

Though $\delta$ does not affect retailer's payment for the manufacturer's emission reduction cost, it does influence the difference of the optimal emission reduction levels between the game with side-payment and that without side-payment. And the increment of optimal emission reduction decreases with $\delta$ but that of the optimal promotion level increases with $\delta$ between different decision-making modes. It means that the bigger $\delta$ is, the less effective the incentive for encouraging the manufacturer to improve carbon cutting is. So as $\delta$ increases, the retailer prefers to invest in promotion but not in sharing the manufacturer's cost. Also the optimal promotion level increases with $\delta$.

(5) As $\gamma$ increases, the optimal profit of the manufacturer decreases; the optimal profit of the retailer firstly decreases and then increases and the total profit of the supply chain decreases. As $\delta$ increases, the optimal profit of the retailer decreases; the optimal profit of the manufacturer decreases firstly and then increases and the total profit of the supply chain decreases.

As $\gamma$ increases, the optimal emission reduction of the manufacturer increases while its optimal profit decreases. But it does not mean that the manufacturer's profit decreases with the emission reduction level when the exogenous variables, such as $\gamma$, are definite. The increasing $\gamma$ means the improving consumer low-carbon awareness. Companies' carbon cutting stress increases with $\gamma$ and they have to improve emission reduction to satisfy consumers. But as a result, the marginal cost of emission reduction increases. So the optimal emission reduction level increases with $\gamma$, but the optimal profit of the manufacturer decreases with $\gamma$. In other words, the manufacturer's optimal emission reduction increases while

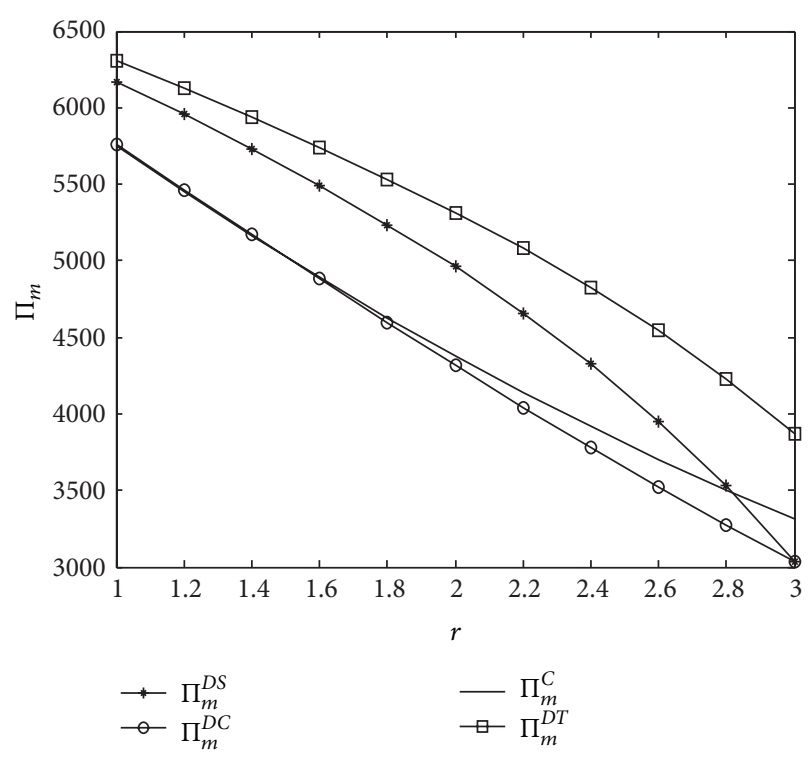

Figure 6: Impact of $\gamma$ on manufacturers profits.

its optimal profit decreases. It means that the total profit of manufacturer and retailer decreases while the consumer utility increases. That is because the negative externality of carbon emission decreases as emission reduction improves.

As emission reduction increases, the product demand increases and the retailer get more profit without raising promotion level. Since the optimal promotion level decreases with $\gamma$ and it results in the reduction of product demand, the optimal profit of the retailer decreases first and then increases. In fact, the balance between the increasing emission reduction and the decreasing promotion level is gradual. Similarly, as $\delta$ increases, the manufacturer's optimal profit decreases firstly and then increases.

An increasing $\delta$ means that promotion's effect on market demand is increasing. In other words, consumer's voice rises in the game between consumer and retailer, so retailer's optimal profit decreases with $\delta$. But when $\delta$ is determined, raising promotion level can improve the retailer's profit really.

Then we get to know that as $\gamma$ and $\delta$ increase, consumers' voice rises in the game between them and companies; consumer surplus increases, but the total profit of the supply chain (including manufacturer and retailer) decreases gradually.

(6) As shown from Figure 8 to Figure 11, the optimal profit of the supply chain in centralized decision-making setting is more than that in decentralized decision-making setting. But as shown in Figures 6, 7, 9, and 10, the same conclusion does not always apply to both of the retailer and the manufacture. So, it is not easy for the retailer and the manufacture, when they make a decision according to individual rationality, to achieve the same decision-making effect in centralized decision-making. Then a new contract is necessary for the supply chain to obtain profit when the players make a decision individually as much as that in centralized decision making. 


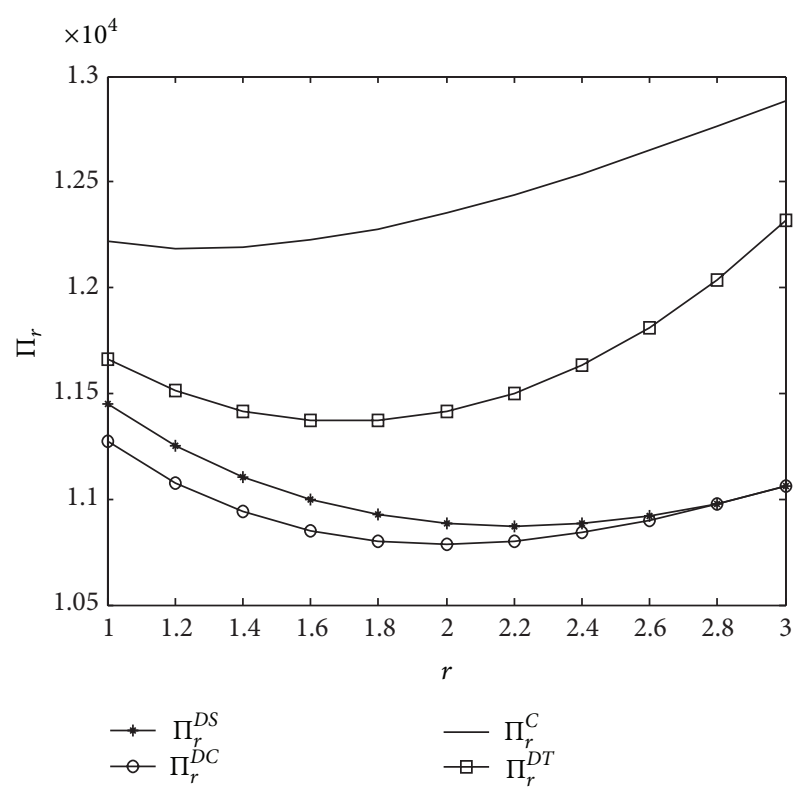

FIGURE 7: Impact of $\gamma$ on retailers profits.

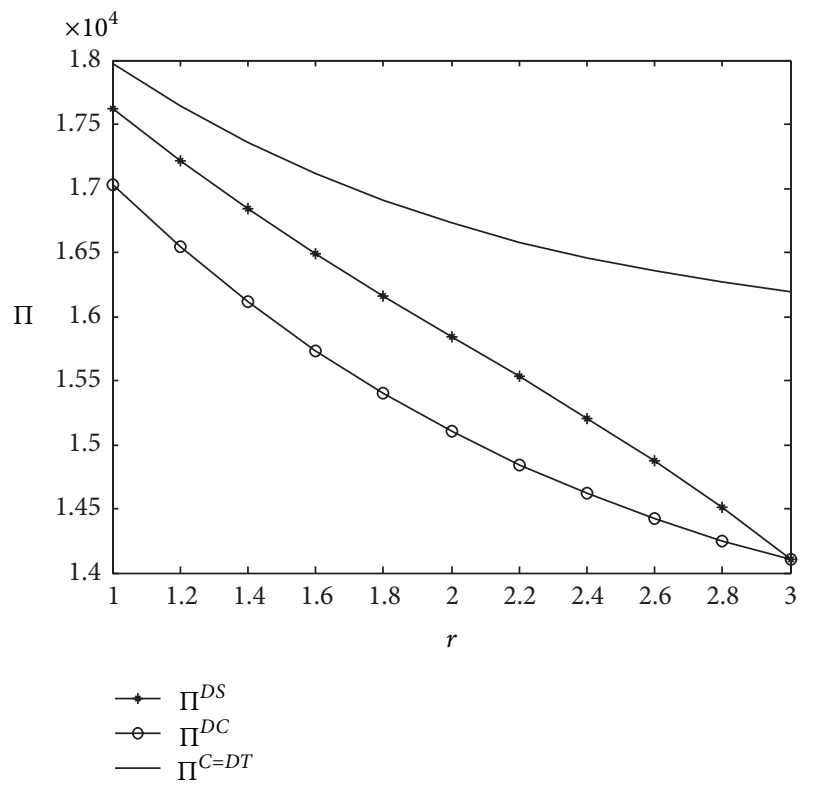

FIGURE 8: Impact of $\gamma$ on supply chain profits.

\section{Conclusion}

It is more and more obvious that carbon emission of product affects market demand as consumer's low-carbon consciousness improves. Retailers play the leading roles in many industries and they tend to take advantage of their buyer power to gain more profit. In fact, the retailer and the manufacture can cooperate and compete at the same time as long as cooperation results in profit increase for both of them. One of the approaches to cooperate is that the retailer pays side-payment for the manufacturer's emission reduction. Although it is helpful for improving profits of both

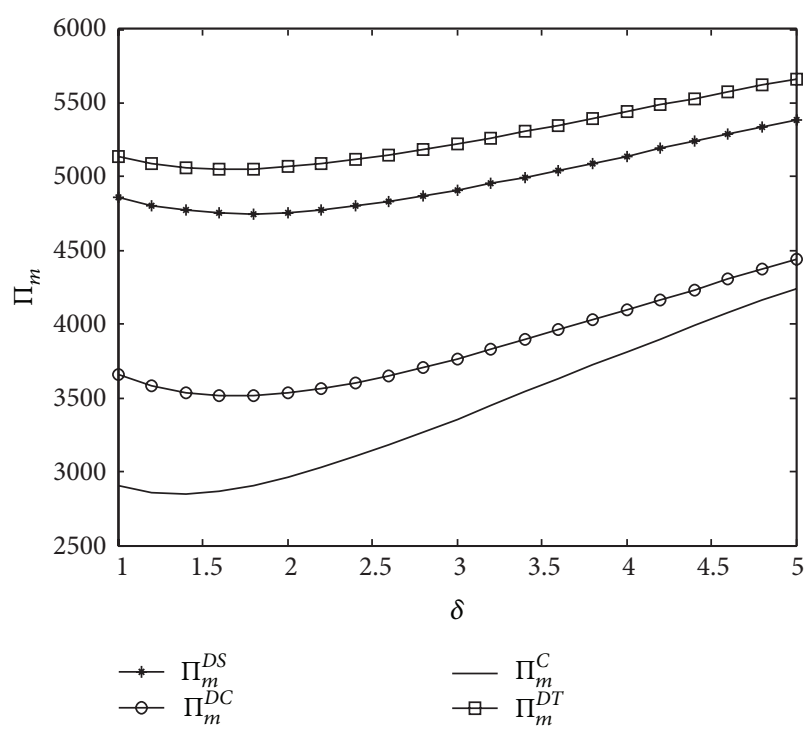

FIGURE 9: Impact of $\delta$ on manufacturers profits.

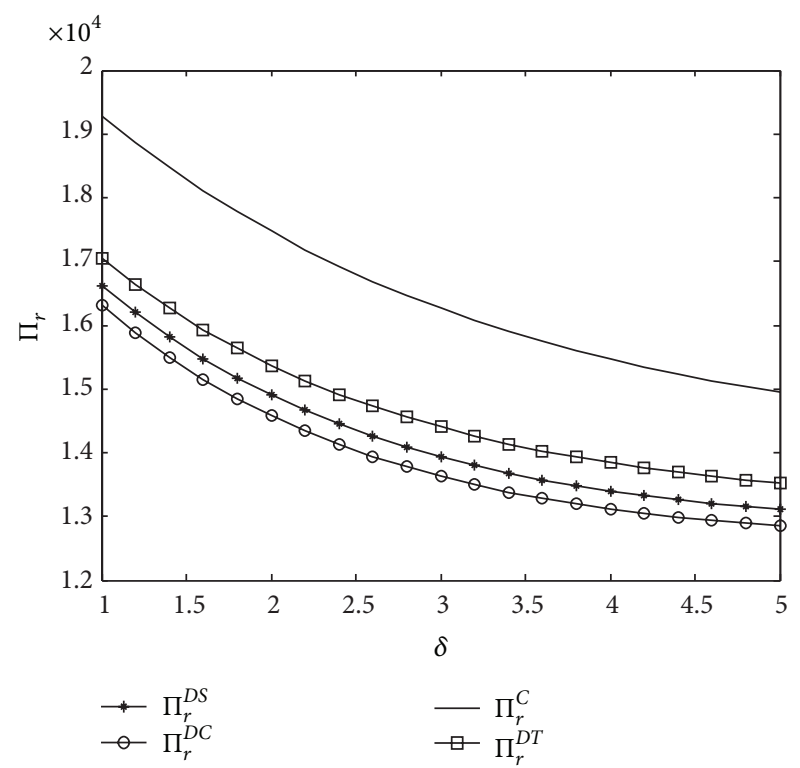

FIGURE 10: Impact of $\delta$ on retailers profits.

of the players, the system profit is not able to achieve Pareto optimality. It is proved that Pareto optimality of the system profit can be gained with the mode of centralized decision, but the allocation of profit must be executed under "fair and reasonable" conditions.

Therefore, this paper analyzes the optimal decisions of the manufacture and the dominant retailer in different game models considering the impact of emission reduction and promotion related to the product's low-carbon feature on product demand. Then, the paper designs a new sidepayment self-executing contract to optimize the system profit and resolve the problem of fairness and reasonability in profit allocation. Our study shows that it is effective to encourage the manufacturer to improve emission reduction by means 


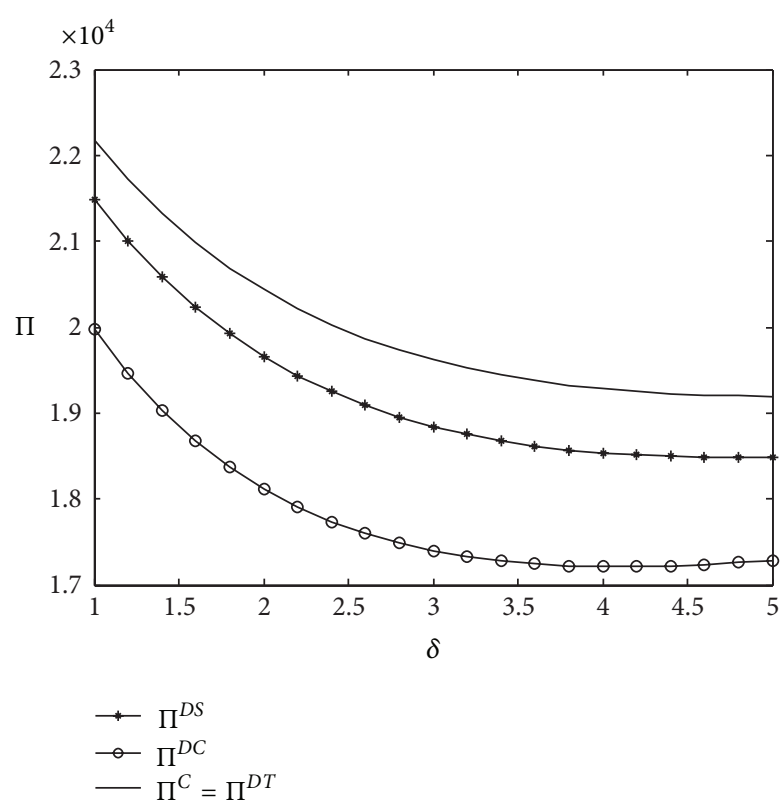

FIGURE 11: Impact of $\delta$ on supply chain profits.

of sharing its cost in carbon cutting. At the same time, the retailer will share the manufacturer's cost only if their marginal profit and consumer's low-carbon consciousness meet certain conditions. Although cost allocation is helpful for improving profits of both of the players, the system profit is not able to achieve Pareto optimality. But the new sidepayment self-executing contract is effective in achieving this goal. At the same time, it is an important approach to realize fairness and reasonability in profit allocation. Numerical analysis shows that the optimal profits of companies decrease, the negative external effect of carbon emission decreases, and the consumer utility increases as consumer's low-carbon consciousness increases.

The paper is based on a two-echelon supply chain with deterministic product demand considering only one retailer and one manufacturer. The research on coordination of supply chain network with stochastic product demand considering carbon regulations is the further research direction.

\section{Appendix}

(1)

$$
\begin{aligned}
\frac{e^{D S}}{e^{D C}}= & \left(\left[\frac{\gamma b\left(2 \rho_{r}-\gamma \rho_{m}\right)}{2 u_{m}}\right]^{(\delta+2) /(2 \gamma+2 \delta+4)}\right. \\
& \left.\times\left[\frac{\delta b\left(2 \rho_{r}-\gamma \rho_{m}\right)}{2 u_{r}}\right]^{-\delta /(2 \gamma+2 \delta+4)}\right) \\
& \times\left(\left[\frac{2 \delta b \rho_{r}}{u_{r}(\gamma+2)}\right]^{-\delta /(2 \delta+2 \gamma+4)}\right.
\end{aligned}
$$

$$
\begin{gathered}
\left.\times\left(\frac{\gamma b \rho_{m}}{u_{m}}\right)^{(\delta+2) /(2 \delta+2 \gamma+4)}\right)^{-1} \\
=\left(\frac{2 \rho_{r}-\gamma \rho_{m}}{2 \rho_{m}}\right)^{(\delta+2) /(2 \gamma+2 \delta+4)} \\
\times\left(\left[\frac{(\gamma+2)\left(2 \rho_{r}-\gamma \rho_{m}\right)}{4 \rho_{r}}\right]^{\delta /(2 \gamma+2 \delta+4)}\right)^{-1}
\end{gathered}
$$

Since $\left(2 \rho_{r}-\gamma \rho_{m}\right) / 2 \rho_{m}>1,\left(\left(2 \rho_{r}-\gamma \rho_{m}\right) / 2 \rho_{m}\right)^{(\delta+2) /(2 \gamma+2 \delta+4)}>$ $\left(\left(2 \rho_{r}-\gamma \rho_{m}\right) / 2 \rho_{m}\right)^{\delta /(2 \gamma+2 \delta+4)}$. Consider

$$
\begin{aligned}
\frac{e^{D S}}{e^{D C}} & =\frac{\left(\left(2 \rho_{r}-\gamma \rho_{m}\right) / 2 \rho_{m}\right)^{(\delta+2) /(2 \gamma+2 \delta+4)}}{\left[(\gamma+2)\left(2 \rho_{r}-\gamma \rho_{m}\right) / 4 \rho_{r}\right]^{\delta /(2 \gamma+2 \delta+4)}} \\
& \geq \frac{\left(\left(2 \rho_{r}-\gamma \rho_{m}\right) / 2 \rho_{m}\right)^{\delta /(2 \gamma+2 \delta+4)}}{\left[(\gamma+2)\left(2 \rho_{r}-\gamma \rho_{m}\right) / 4 \rho_{r}\right]^{\delta /(2 \gamma+2 \delta+4)}} \\
& =\left[\frac{2 \rho_{r}}{\rho_{m}(\gamma+2)}\right]^{\delta /(2 \gamma+2 \delta+4)} \geq 1 ;
\end{aligned}
$$

that is, $e^{D S}>e^{D C}$. Consider

(2)

$$
\begin{aligned}
q^{D S}-q^{D C}= & \left(\frac{\delta b}{u_{r}}\right)^{(\gamma+2) /(2 \delta+2 \gamma+4)}\left(\frac{\gamma b}{u_{m}}\right)^{-\gamma /(2 \delta+2 \gamma+4)} \\
& \times\left[\left(\frac{2 \rho_{r}-\gamma \rho_{m}}{2}\right)^{2 /(2 \gamma+2 \delta+4)}\right. \\
& \left.-\left(\frac{2 \rho_{r}}{\gamma+2}\right)^{(\gamma+2) /(2 \delta+2 \gamma+4)} \rho_{m}^{-\gamma /(2 \delta+2 \gamma+4)}\right] .
\end{aligned}
$$

Since

$$
\left(\frac{\delta b}{u_{r}}\right)^{(\gamma+2) /(2 \delta+2 \gamma+4)}\left(\frac{\gamma b}{u_{m}}\right)^{-\gamma /(2 \delta+2 \gamma+4)}>0
$$

$q^{D S}>\underset{q^{D C}}{ }$ if $\left(\left(2 \rho_{r}-\gamma \rho_{m}\right) / 2\right)^{2 /(2 \gamma+2 \delta+4)}-$
$\left(2 \rho_{r} /(\gamma+2)\right)^{(\gamma+2) /(2 \delta+2 \gamma+4)} \rho_{m}-\gamma /(2 \delta+2 \gamma+4)>0$; otherwise $q^{D S} \leq q^{D C}$

(3) In the Stackelberg game with side-payments $\left(e^{D S}, q^{D S}\right.$, $\left.\theta^{D S}\right)$ is the unique optimal solution for the retailer. So the retailer's profit in this case is more than the case that the 
emission reduction, promotion level, and cost sharing is $e^{D C}$, $q^{D C}$, and $\theta=0$, respectively. Consider

$$
\begin{aligned}
\max \Pi_{r}^{D C}= & \rho_{r}\left[a-b\left(e^{D S}\right)^{-\gamma}\left(q^{D S}\right)^{-\delta}\right] \\
& -\frac{1}{2} \theta^{D S} u_{m}\left(e^{D S}\right)^{2}-\frac{1}{2} u_{r}\left(q^{D S}\right)^{2} \\
> & \rho_{r}\left[a-b\left(e^{D S^{\prime}}\right)^{-\gamma}\left(q^{D S^{\prime}}\right)^{-\delta}\right]-\frac{1}{2} u_{r}\left(q^{D S^{\prime}}\right)^{2} \\
= & \max \Pi_{r}^{D C} .
\end{aligned}
$$

For the manufacturer,

$$
\begin{aligned}
\max & \Pi_{m}^{D S}-\max \Pi_{m}^{D C} \\
= & b \rho_{m}\left[\left(e^{D C}\right)^{-\gamma}\left(q^{D C}\right)^{-\delta}-\left(e^{D S}\right)^{-\gamma}\left(q^{D S}\right)^{-\delta}\right] \\
+ & \frac{1}{2} u_{m}\left[\left(e^{D C}\right)^{2}-\left(1-\theta^{D S}\right)\left(e^{D S}\right)^{2}\right] \\
= & b \rho_{m} \frac{\gamma+2}{2}\left(\frac{\delta b}{u_{r}}\right)^{-2 \delta /(2 \delta+2 \gamma+4)}\left(\frac{\gamma b}{u_{m}}\right)^{-2 \gamma /(2 \delta+2 \gamma+4)} \\
\times & {\left[\rho_{m}{ }^{-2 \gamma /(2 \delta+2 \gamma+4)}\left(\frac{2 \rho_{r}}{\gamma+2}\right)^{-2 \delta /(2 \delta+2 \gamma+4)}\right.} \\
& \left.\quad\left(\frac{2 \rho_{r}-\gamma \rho_{m}}{2}\right)^{(-2 \delta-2 \gamma) /(2 \gamma+2 \delta+4)}\right]
\end{aligned}
$$

since

$$
\begin{gathered}
\rho_{r}>\frac{1}{2}(\gamma+2) \rho_{m}, \quad \rho_{m}<\frac{2 \rho_{r}-\gamma \rho_{m}}{2}, \\
\frac{2 \rho_{r}}{\gamma+2}-\frac{2 \rho_{r}-\gamma \rho_{m}}{2}=\frac{\gamma\left(\gamma \rho_{m}+2 \rho_{m}-2 \rho_{r}\right)}{4+2 \gamma}<0,
\end{gathered}
$$

so $\rho_{m}{ }^{-2 \gamma /(2 \delta+2 \gamma+4)}\left(2 \rho_{r} /(\gamma+2)\right)^{-2 \delta /(2 \delta+2 \gamma+4)}-\left(\left(2 \rho_{r}-\gamma \rho_{m}\right) /\right.$ $2)^{(-2 \delta-2 \gamma) /(2 \gamma+2 \delta+4)}>0, \max \Pi_{m}^{D S}-\max \Pi_{m}^{D C}>0$.

We have $\max \Pi_{r}^{D S}>\max \Pi_{r}^{D C}, \max \Pi_{m}^{D S}>\max \Pi_{m}^{D C}$, and obviously $\max \Pi^{D S}>\max \Pi^{D C}$.

\section{Conflict of Interests}

The authors declare that there is no conflict of interests regarding the publication of this paper.

\section{Acknowledgments}

The authors would like to express their sincere thanks to the anonymous referees and editors for their time and patience devoted to the review of this paper. This work is partially supported by NSFC Grant (no. 71202086), the Scientific Research Development Fund of Tianjin University of Finance and Economy (no. Q130204), and Training Program for Innovation Teams of Universities in Tianjin (no. TD12-5051).

\section{References}

[1] H. Geller, P. Harrington, A. H. Rosenfeld, S. Tanishima, and F. Unander, "Polices for increasing energy efficiency: thirty years of experience in OECD countries," Energy Policy, vol. 34, no. 5, pp. 556-573, 2006.

[2] Carbon Trust, Carbon Footprint Measurement Methodology, Version 1.1, The Carbon Trust, London, UK, 2007, http://www.carbontrust.co.uk.

[3] Z. Liu, T. D. Anderson, and J. M. Cruz, "Consumer environmental awareness and competition in two-stage supply chains," European Journal of Operational Research, vol. 218, no. 3, pp. 602-613, 2012.

[4] R. Inderst and C. Wey, "Buyer power and supplier incentives," European Economic Review, vol. 51, no. 3, pp. 647-667, 2007.

[5] T. Geylani, A. J. Dukes, and K. Srinivasan, "Strategic manufacturer response to a dominant retailer," Marketing Science, vol. 26, no. 2, pp. 164-178, 2007.

[6] J. Han, D. Zhao, and J. Qin, "Bertrand evolutionary game analysis of duopoly upstream suppliers behavior," Journal of Management Sciences, vol. 22, no. 2, pp. 57-63, 2009.

[7] G. P. Cachon, "Supply chain coordination with contracts," in Handbooks in Operations Research and Management Science: Supply Chain Management: Design, Coordination and Operation, S. Graves and A.G. de Kok, Eds., pp. 227-339, Amsterdam, The Netherlands, 2003.

[8] M. Leng and A. Zhu, "Side-payment contracts in two-person nonzero-sum supply chain games: review, discussion and applications," European Journal of Operational Research, vol. 196, no. 2, pp. 600-618, 2009.

[9] D. Luo and X. Zhang, "The study of the side-payment incentive mechanism of the decentralized supply chain," Journal of Systems Engineering, vol. 16, no. 3, pp. 236-240, 2001.

[10] H. Tang, J. He, and C. Liu, "Research of a class of linear supply chain side-payment incentive mechanism," Chinese Journal of Management Science, vol. 11, no. 6, pp. 29-34, 2003.

[11] K. Schultz and P. Williamson, "Gaining competitive advantage in a carbon-constrained world: strategies for European business," European Management Journal, vol. 23, no. 4, pp. 383-391, 2005.

[12] S. Benjaafar, Y. Li, and M. Daskin, "Carbon footprint and the management of supply chains: insights from simple models," IEEE Transactions on Automation Science and Engineering, vol. 10, no. 1, pp. 99-116, 2013.

[13] E. Masanet, K. J. Kramer, G. Homan et al., Assessment of Household Carbon Footprint Reduction Potentials, California Energy Commission, Sacramento, Calif, USA, 2008.

[14] K. M. R. Hoen, T. Tan, C. J. Fransoo et al., "Switching transport modes to meet voluntary carbon emission targets," Transportation Science, 2013.

[15] K. M. R. Hoen, T. Tan, J. C. Fransoo et al., "Effect of carbon emission regulations on transport mode selection under stochastic demand," Flexible Services and Manufacturing Journal, vol. 26, no. 1-2, pp. 170-195, 2014.

[16] S. Elhedhli and R. Merrick, "Green supply chain network design to reduce carbon emissions," Transportation Research Part D: Transport and Environment, vol. 17, no. 5, pp. 370-379, 2012.

[17] A. Ramudhin, A. Chaabane, M. Kharoune, and M. Paquet, "Carbon market sensitive green supply chain network design," in Proceedings of the IEEE International Conference on Industrial Engineering and Engineering Management (IEEM'08), pp. 1093 1097, Singapore, December 2008. 
[18] A. Diabat and D. Simchi-Levi, "A carbon-capped supply chain network problem," in Proceedings of the IEEE International Conference on Industrial Engineering and Engineering Management (IEEM’09), pp. 523-527, Hong Kong, December 2009.

[19] G. P. Cachon, "Supply chain design and the cost of greenhouse gas emissions," Working Paper, University of Pennsylvania, 2011.

[20] K. H. Lee, "Integrating carbon footprint into supply chain management: the case of Hyundai Motor Company (HMC) in the automobile industry," Journal of Cleaner Production, vol. 19, no. 11, pp. 1216-1223, 2011.

[21] F. Caro, C. Corbett, T. Tan, and R. Zuidwijk, "Carbon-optimal and carbon-neutral supply chains," Working Paper, Anderson Graduate School of Management-Decisions, Operations, and Technology Management, Los Angeles, Calif, USA, 2011.

[22] S. Du, F. Ma, Z. Fu et al., "Game-theoretic analysis for an emission-dependent supply chain in a cap-and-tradesystem," Annals of Operations Research, pp. 1-15, 2011.

[23] L. Xia, D. Zhao, and Y. Li, "Game on jointly emission reduction based on transfer payment contract between the supplier and the manufacturer," Systems Engineering, vol. 31, no. 8, pp. 39-46, 2013.

[24] J. Yang, J. Li, and W. Lu, "The impact of emission policies on supply chain based on system dynamics," Industrial Engineering and Management, vol. 17, no. 4, pp. 21-30, 2012.

[25] M. Laroche, J. Bergeron, and G. Barbaro-Forleo, "Targeting consumers who are willing to pay more for environmentally friendly products," Journal of Consumer Marketing, vol. 18, no. 6, pp. 503-520, 2001.

[26] E. L. Plambeck, "Reducing greenhouse gas emissions through operations and supply chain management," Energy Economics, vol. 34, no. 1, pp. S64-S74, 2012.

[27] S. Jing, "The analysis on green marketing and its impact on consumer psychology and behavior," Management World, no. 5, pp. 145-146, 2004.

[28] T. A. Taylor, "Supply chain coordination under channel rebates with sales effort effects," Management Science, vol. 48, no. 8, pp. 992-1007, 2002.

[29] J. Yue, J. Austin, M. Wang, and Z. Huang, "Coordination of cooperative advertising in a two-level supply chain when manufacturer offers discount," European Journal of Operational Research, vol. 168, no. 1, pp. 65-85, 2006.

[30] J. G. Szmerekovsky and J. Zhang, "Pricing and two-tier advertising with one manufacturer and one retailer," European Journal of Operational Research, vol. 192, no. 3, pp. 904-917, 2009.

[31] R. Jones and H. Mendelson, "Information goods vs. industrial goods:cost structure and competition," Management Science, vol. 57, no. 1, pp. 164-176, 2011.

[32] L. F. He and D. Zhao, "Side-payment self-enforcing contract based supply chain dynamic game coordination," System Engineering-Theory \& Practice, vol. 31, no. 10, pp. 1864-1878, 2011.

[33] A. Rubinstein, "Perfect equilibrium in a bargaining model," Econometrica, vol. 50, no. 1, pp. 97-109, 1982. 


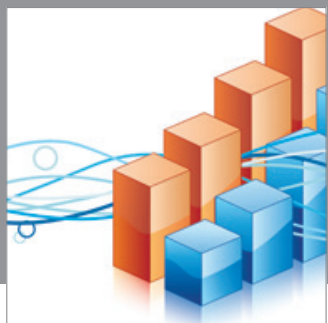

Advances in

Operations Research

mansans

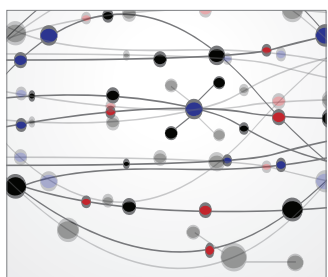

The Scientific World Journal
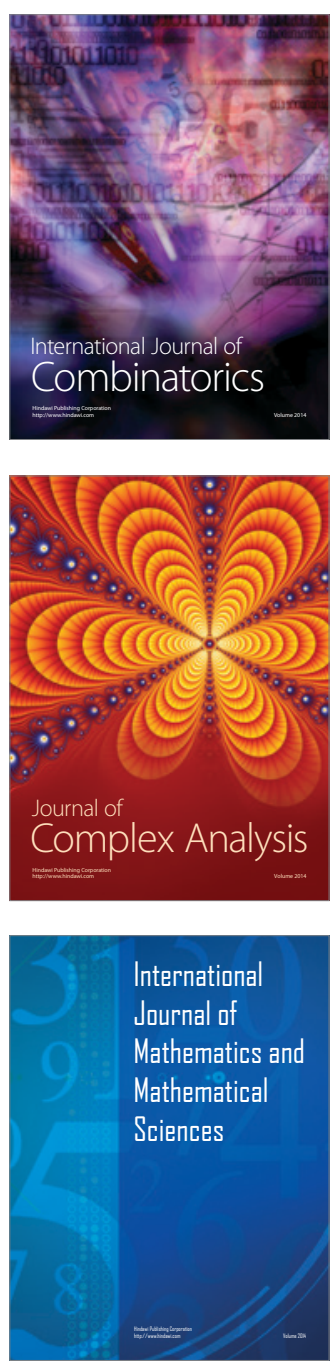
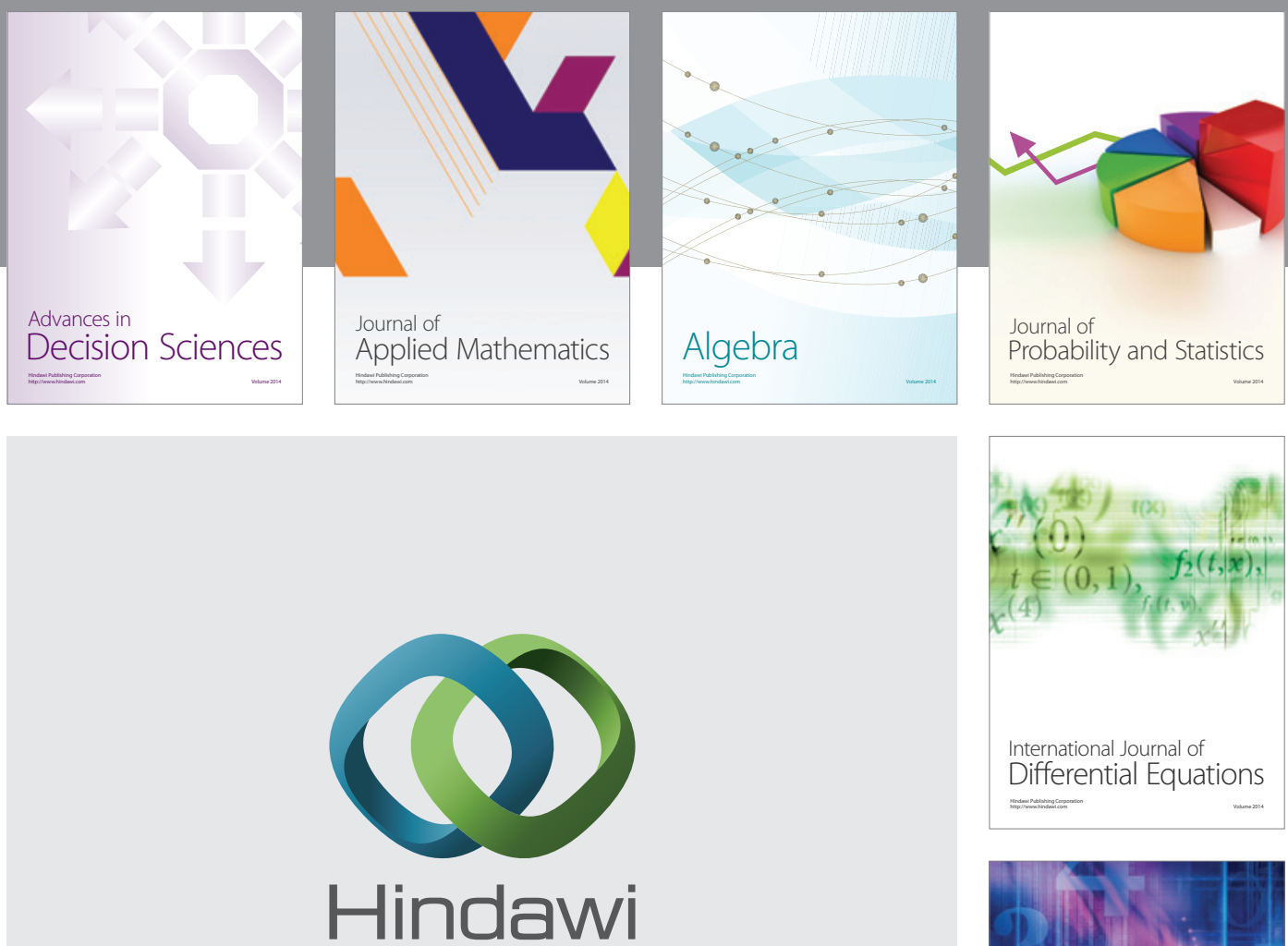

Submit your manuscripts at http://www.hindawi.com
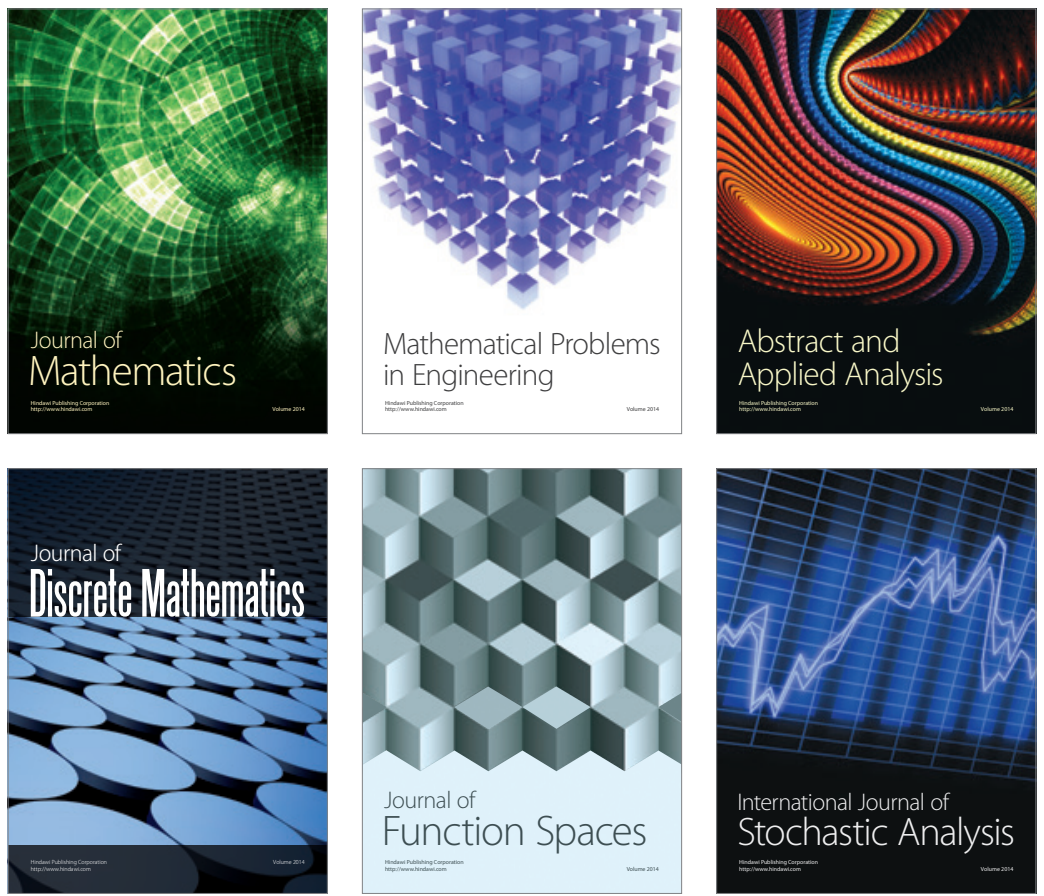

Journal of

Function Spaces

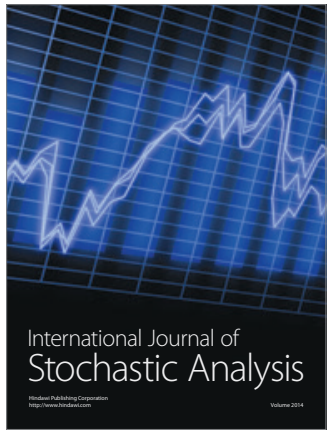

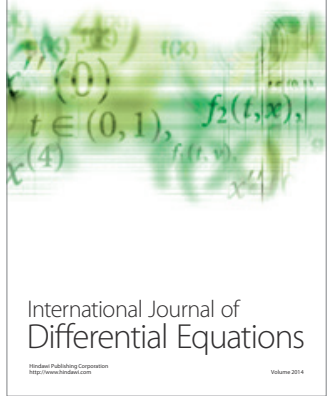
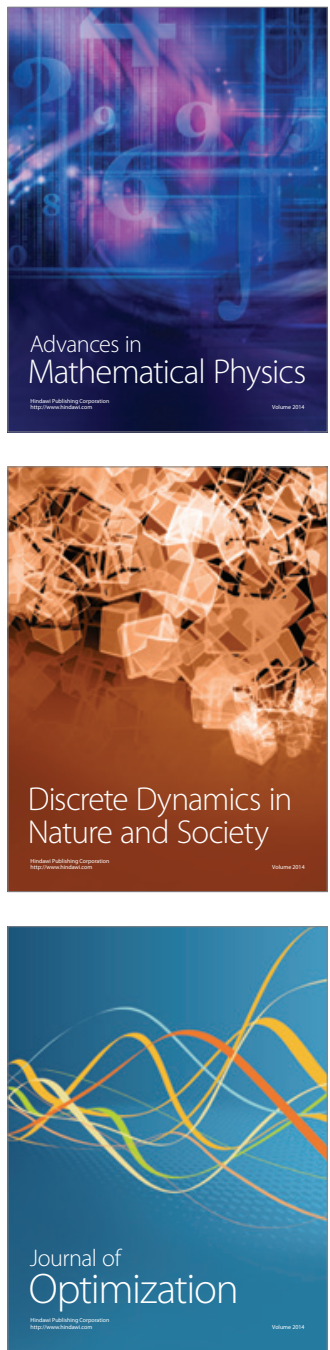